range $60-120 \mu \mathrm{M}]$ ). Other adverse effects noted which did not delay or stop treatmen included tachycardia (one patient), fall in haemoglobin (one), persistent pyrexia (one), nausea and vomiting (four), limb or chest pain (four), rigors (two), and headache (two). It was noted that there was no consensus on the level of leucopenia, neutropenia, raised urea, or creatinine at which treatment was discontinued among the six consultant neurologists at the centre. During a 5 day course, the white cell count was noted to fall below $4 \times 10^{9} / 1$ in 12 patients and the neutrophil count to below $2.0 \times 10^{9} / 1$ in eight patients. Urea and creatinine concentration only became abnormal in one patient (who developed renal failure requiring haemodialysis) whose renal function was mildly impaired before treatment (sodium $133 \mathrm{mM}$, potassium $4.6 \mathrm{mM}$, urea $7.0 \mathrm{mM}$, and creatinine $138 \mu \mathrm{M})$. In all patients with noted haematological derangement secondary to IVIg treatment, subsequent blood monitoring 14 days after stopping treatment showed a return to normal values.

The number of patients who had abnormal blood variables during this retrospective study suggests a need to establish guidelines for monitoring haematological and renal variables during IVIg therapy. Furthermore, given the cost implications of an abortive course of IVIg treatment, guidelines for a tolerable level of leucopenia, neutropenia, or urea/creatinine derangement during a standard 5 day course of IVIg also needs to be established. It may well be that neutropenia during IVIg treatment is transient and reversible, as suggested by this study, and if validated, there would be an argument against the need for regular haematological monitoring during IVIg therapy. This argument is supported by the findings of Koffman et $a l^{3}{ }^{3}$ who retrospectively reviewed the records of 46 patients with neuromuscular disease receiving standard courses of IVIg (Gamimune N (Bayer) $2 \mathrm{~g} / \mathrm{kg}$ ) compared with 23 patients given placebo infusions of dextrose in water. In this study leucopenia, neutropenia, and lymphopenia were noted in a large proportion of patients treated with IVIg. Despite this no significant side effects - for example, infection - resulted and all haematological derangements were transient.

Furthermore, consensus needs to be established on the effect of IVIg formulation and risk of sucrose nephropathy (sucrose is used as a stabiliser in some IVIg preparations). Some previous case reports have suggested a link between the use of high sucrose formulations of IVIg (for example, Sandoglobulin (Novartis)) and subsequent renal failure compared with the use of lower sugar or glycine based formulations. ${ }^{4}$ However, a recent report by Levy and Pusey ${ }^{5}$ comparing Vigam (BPL; 0.5 g sucrose/g immunoglobulin) and Sandoglobulin (Novartis: $1.76 \mathrm{~g}$ sucrose/g immunoglobulin) in various indications has shown no such correlation between concentration of sucrose stabiliser in IVIg and propensity to cause renal failure. In their study of 119 patients given 287 courses of IVIg, eight patients $(6.7 \%)$ showed a deterioration in renal function regardless of preparation used. On this basis, they concluded that all patients given IVIg should have renal function monitored before, during, and $4-5$ days after treatment. This should be compared with the study of Koffman et al, ${ }^{3}$ where none of the 46 patients given the same preparation of high dose IVIg had renal dysfunction.
Our current practice, based on the results of this audit and the literature available, is to check the renal function of all patients before IVIg therapy. Those in whom the renal function is mildly abnormal (normal sodium and potassium, urea 7-8 $\mathrm{mM}$, and creatinine $120-150 \mu \mathrm{M}$ ) have their renal function monitored during and 5 days after IVIg treatment and are currently receiving low sucrose or no sucrose (Octogam(Octopharma)) IVIg formulations. Patients with more seriously impaired renal function are not being considered for IVIg therapy; alternative modes of treatmentfor example, plasmapharesis-could be considered for this subgroup. Haematological function is also checked before IVIg therapy; if normal, no further monitoring is carried out during or after IVIg treatment. If there is evidence of mild leucopenia, neutropenia, or thrombocytopenia before IVIg, the full blood count is monitored on a daily basis during treatment and once more 5 days after treatment. Patients with more severe blood derangement (platelets $<100 \times 10^{9} / 1$, neutrophil count $<1 \times 10^{\circ} / 1$, and leucocyte count $<2 \times 10^{\%} / 1$ ) are not being considered for IVIg therapy and again alternative modes of therapy would be considered.

A consensus statement on the recommended duration of treatment course (1-2 days $v 5$ days) and the requirements for blood monitoring during IVIg infusion will require further study and collaborative audit across the many neurological centres in the United Kingdom using this form of therapy. We think that the potential cost implications and side effect profile of IVIg justify a call for such a study.

We thank Professor Richard Hughes for his help in the preparation of this manuscript.

N P S BAJAJ N HENDERSON R BAHL K STOTT

R E CLIFFORD-JONES

Departments of Neurology and Pharmacy, Hurstwood Park Neurological Centre (HPNC), Hurstwood Lane, West Sussex, UK

Correspondence to: Dr N P S Bajaj, Department of Neurology, National Hospital for Neurology and Neurosurgery, Queen Square, London WC1 3BG, UK

narinderbajaj@compuserve.com

1 Brannagan TH, Nagle K, Lange DJ, et al. Complications of intravenous immune globulin treatment in neurologic disease. Neurology 1996;47:675-77.

2 Dalakas MC. Mechanism of action of intravenous immunoglobulin and therapeutic considerations in the treatment of autoimmune neurologic diseases. Neurology 1998;51(S5): S2-8.

Table 1 Neurological and neuropsychological findings

\begin{tabular}{lccccc}
\hline & \multicolumn{2}{l}{ Pallidotomy group } & & \multicolumn{2}{l}{ Control group } \\
\cline { 2 - 3 } \cline { 5 - 6 } & $\begin{array}{l}\text { Initial } \\
\text { evaluation }\end{array}$ & $\begin{array}{l}\text { Follow up } \\
\text { evaluation }\end{array}$ & & $\begin{array}{l}\text { Initial } \\
\text { evaluation }\end{array}$ & $\begin{array}{l}\text { Follow up } \\
\text { evaluation }\end{array}$ \\
\hline Mini mental state examination & $26.4(3.4)$ & $25.3(3.3)$ & & $26.3(3.3)$ & $27.5(2.2)$ \\
UPDRS motor score & $15.4(7.8)$ & $10.8(5.3)$ & & $18.8(15.8)$ & $15.1(9.0)$ \\
Levodopa dosage & $785(379)$ & $775(429)$ & & $590(346)$ & $890(711)$ \\
Raven's progressive matrices & $39.9(33.8)$ & $53.9(36.1)$ & & $59.8(36.5)$ & $62.2(34.3)$ \\
Wisconsin card sorting test & $3.7(2.1)$ & $4.0(2.5)$ & & $4.6(1.9)$ & $4.9(1.9)$ \\
Verbal fluency & $33.0(8.9)$ & $37.3(6.4)$ & & $38.8(9.8)$ & $41.0(13.4)$ \\
Buschke total recall & $65.4(22.2)$ & $69.4(17.5)$ & & $76.7(18.1)$ & $70.5(15.3)$ \\
Buschke delayed & $3.3(3.1)$ & $5.5(3.0)$ & & $6.8(3.0)$ & $5.8(2.5)$ \\
Benton visual retention test & $5.7(3.0)$ & $7.1(2.6)$ & & $7.7(2.0)$ & $7.5(2.1)$ \\
Digits forward & $5.3(0.8)$ & $5.0(1.0)$ & & $5.7(1.1)$ & $5.6(0.9)$ \\
Digits backwards & $3.6(0.8)$ & $3.8(0.8)$ & & $4.2(1.0)$ & $4.4(1.0)$ \\
Perdue pegboard test & $14.0(5.5)$ & $17.9(2.6)$ & & $19.3(5.5)$ & $18.9(6.4)$ \\
\hline
\end{tabular}

Values are means $(\mathrm{SD})$

${ }^{\star} F(1,28)=8.84 ; \mathrm{p}<0.01$
3 Koffman BM, Dalakas MC. Effect of high-dose intravenous immunoglobulin on serum chemistry, haematology, and lymphocyte subpopulations: assessments based on controlled treatment trials in patients with neurologic diseases. Muscle Nerve 1997;9:1102-7.

4 Haskin JA, Warner DJ, Blank DU. Acute renal failure after large doses of intravenous immunoglobulin. Annals of Pharmacotherapy 1999; 33:800-3.

5 Levy JB, Pusey CD. Nephrotoxicity of intravenous immunoglobulin. $Q$ f Med 2000;93: $751-5$.

\section{Neuropsychological effects of} pallidotomy in patients with Parkinson's disease

Whether patients with Parkinson's disease develop cognitive impairments or improvements after ventral pallidotomy is still a debated issue. ${ }^{1}$ Recent studies produced contradictory findings which may have resulted from methodological factors such as differences in surgical techniques, neuropsychological assessments, duration of follow up, and the lack of evaluations of non-operated controls with Parkinson's disease. ${ }^{1}$

We assessed a consecutive series of 27 patients with Parkinson's disease who received unilateral pallidotomy using the microelectrode registration technique. ${ }^{2}$ Sixteen of these patients received a 3-6 month follow up evaluation, and 10 of them received a 12 month follow up evaluation. They were compared with a non-operated control group of 20 patients with Parkinson's disease matched for age, severity of extrapyramidal symptoms, and overall cognitive status who received the same neuropsychological evaluation at baseline and 12 months later. The neuropsychological examination included the Raven's progressive matrices, the Wisconsin card sorting test (WCST), the controlled oral word association test, the Buschke selective reminding test, the Benton visual retention test, the digit span, and the Perdue pegboard.

No significant differences between the pallidotomy and the control groups were found (6.9), control group 59.3 (7.9)), sex (pallidotomy group 50\% women, control group: $50 \%$ women), years of education (years (SD) pallidotomy group10.7 (2.7), control group: 11.4 (4.1)), baseline levodopa equivalent dosage, and UPDRS total scores (table 1). All patients were right handed.

Sixteen patients with Parkinson's disease who underwent unilateral pallidotomy received a 3-6 month follow up. A repeated measures multivariate analysis of variance (MANOVA) for the neuropsychological variables comparing baseline versus 3-6 month for age (years (SD) pallidotomy group 56.3 
follow up evaluation showed no significant overall time effect $(F(7,56)=1.01$; NS). There was a significant time effect for the Perdue pegboard test $(F(1,14)=30.9$; $\mathrm{p}<0.0001$ ), with a significant improvement in manipulative dexterity over time. A repeated measures MANOVA for the neuropsychological variables comparing patients with either a left $(n=7)$ or right $(n=9)$ pallidotomy showed no significant group effect $(\mathrm{F}(1,7)=0.05 ; \mathrm{NS})$, time effect $(F(1,7)=1.03$; NS), or group $\times$ time interaction $(F(8,56)=0.22 ; \mathrm{NS})$.

A repeated measures MANOVA for the neuropsychological variables for the $10 \mathrm{pa}-$ tients who had undergone pallidotomy (six right, four left) with a 12 month follow up and the 20 non-operated patients with Parkinson's disease did not show a significant group effect $(F(1,23)=0.29 ; \mathrm{NS})$, time effect $(F(1,23)=0.43$; NS), or group $\times$ time interaction $(F(7,161)=0.18$; NS). On the other hand, there was a significant group $\times$ time interaction for the Perdue pegboard test $(F(1,28)=8.84 ;$ p $<0.01)$ : the pallidotomy group showed a significant improvement during the follow up period, whereas the control group had a slight decline.

Most studies on the cognitive sequelae of pallidotomy could not show significant neuropsychological deficits after surgery, and the only studies that to our knowledge included a non-operated Parkinson's disease control group (Perrine $e t a l^{4}$ and the present one) confirmed this finding. On the other hand, Lang et ap reported some cognitive impairments after ventral pallidotomy; and differences in neuropsychological outcome measures may account for this discrepancy. We examined the neuropsychological sequelae of pallidotomy in a consecutive series of 16 patients with Parkinson's disease, 10 of whom had a 1 year follow up evaluation. When compared with a group of 20 patients with Parkinson's disease matched for MMSE scores and age who did not receive a pallidotomy, no significant between group differences were found in the rate of cognitive changes. On the other hand, the pallidotomy group showed a significant improvement on a task measuring manual dexterity compared with the control Parkinson's disease group. The question now arises as to why pallidotomy in Parkinson's disease does not produce significant cognitive deficits, given that some case reports described various intellectual problems after spontaneous pallidal lesions. Firstly, most lesion studies included patients with bilateral lesions, whereas pallidotomy is usually performed on one side only. The few reports of bilateral pallidotomy in Parkinson's disease described important cognitive sequelae in some of the patients. Secondly, pallidotomy usually produces a small and localised lesion, whereas spontaneous pallidal lesions are usually larger and often involve white matter tracts next to the pallidum. Finally, some of our pallidotomy patients were tested three or four times, compared with only two neuropsychological evaluations for the control group, which may have produced some learning effects.

This study was partially supported by a grant from the Raul Carrea Institute of Neurological ResearchFLENI and the Fundación Perez Companc. We thank Fred Bylsma PhD for his useful suggestions.

G KUZIS

L SABE

C TIBERTI

F DORREGO

S STARKSTEIN

Department of Neuropsychiatry, Raúl Carrea Institute of Neurological Research FLENI, Montañeses 2325, 1428 Buenos Aires, Argentina

M MERELLO S STARKSTEIN

Department of Clinical Neurology

Correspondence to: Dr G Kuzis

ses@fleni.org.ar

1 Scott RB. Cognitive function and pallidotomy. $\mathscr{f}$ Neurol Neurosurg Psychiatry 1998;65:148.

2 Merello M, Nouzeilles M, Kuzis G, et al. UnilatMerello $M$, Nouzeilles $M$, Kuzis $G$, et al. Unilat-
eral radiofrequency lesion versus electrostimueral radiofrequency lesion versus electrostimu-
lation of posteroventral pallidum: a prospective lation of posteroventral pallidum: a prospective
randomized comparison. Mov Disord 1999;14: rando

3 Lund-Johansen M, Hugdahl K, Wester K. Cognitive function in patients with Parkinson's disease undergoing stereotaxic thalamotomy. $f$ Neurol Neurosurg Psychiatry 1996;60:564-71.

4 Perrine K, Dogali M, Fazzini E, et al. Cognitive functioning after pallidotomy for refractory Parkinson's disease. F Neurol Neurosurg Psychiatry 1998;65:150-4.

5 Lang AE, Lozano A, Tasker R, et al. Neuropsychological and behavioral changes and
weight gain after medial pallidotomy. Ann Neurol 1997;41:834-5.

\section{Response to botulinum toxin in a case of rigid spine syndrome}

First described by Dubowitz in $1965,{ }^{1}$ rigid spine syndrome represents an axial congenital merosin positive muscular dystrophy with early, predominant rigidity of the spine as its main characteristic trait. The illness begins at an early age with a delay in motor development, and affects more boys than girls; however, in some cases onset occurs slightly later when weakness of proximal limb muscles appears in a previously otherwise asymptomatic child. In all cases a limitation of neck and trunk flexion develops and scoliosis appears either simultaneously or in the ensuing years; later on the disease may progress slowly or tend to stabilise. Other features that accompany the musculoskeletal signs are respiratory disturbances and cardiac changes. ${ }^{2}$ Recently, a first locus for this syndrome has been identified on chromosome $1 \mathrm{p} .^{3}$ In laboratory studies serum creatine kinase concentrations can be raised. Electromyographic studies of paracervical musculature, trapezium, deltoid, biceps, and quadriceps show a myopathic pattern with normal nerve conduction velocities. Biopsy findings disclose non-specific myopathic changes with descriptions of type I fibre predominance, type II fibre predominance and fibre type disproportion; electron microscopic studies have detected the presence of $\mathrm{Z}$ band streaming.

It is important to distinguish rigid spine syndrome from other diseases in which rigidity of the spine can appear, such as Duchenne and Becker's muscular dystrophies, and principally from Emery-Dreifuss muscular dystrophy and from early onset ankylosing spondylitis, as prognoses are different. The rigid spine sign has also been reported in Bethlem myopathy and congenital myopathies such as nemaline myopathy. As in other muscular dystrophies, no more than supportive care can be offered to patients with rigid spine syndrome; surgical correction has been attempted on one occasion with success. ${ }^{4}$ Here we report a good response to botulinum toxin type A (BOTOX) treatment in a young man with rigid spine syndrome.

A 15 year old boy born at term, with congenital hypospadias surgically corrected and normal psychomotor development, was being studied by an endocrinologist because of short stature (mother's stature $145 \mathrm{~cm}$, father's stature $169 \mathrm{~cm}$ ) who noticed progressive neck flexion limitation and referred him to our institution. At admission on 8 July 1996, he complained of back pain since the previous year, which was more severe at rest; his mother had noticed a gait disturbance and that his back was progressively bending forward. General examination was normal; neurological examination showed no abnormal findings, and strength was completely preserved in all four limbs. He had marked postural kyphosis and contracture of neck extensors severely limiting movement in the anterior and lateral senses; hip flexion was severely affected (below $30^{\circ}$ ); no pain was produced by sacral manoeuvres. Radiological examination of the cervicothoracic spine showed scoliosis without vertebral malformations, $65^{\circ}$ cervical lordosis involving $\mathrm{C} 2$ to $\mathrm{C} 7$, and a $55^{\circ}$ thoracic kyphosis involving T3 to T12. Routine blood testing showed no abnormalities and creatine kinase concentrations were normal; autoantibodies routinely tested were negative. Complete spine MRI studies ruled out vertebral malformations. An ECG and radiography of the chest were normal. Radiological study of sacral joints was normal and the patient was not HLA-B27 positive. An EMG study showed a myopathic pattern (paraspinal musculature, periscapular musculature, and right quadriceps) with

Table 1 Schedule, place, and amount of botulinum toxin injection

\begin{tabular}{|c|c|c|c|c|c|c|}
\hline \multirow[b]{2}{*}{ Injected muscle } & \multicolumn{2}{|l|}{1996} & \multicolumn{3}{|l|}{1997} & \multirow{2}{*}{$\begin{array}{l}1998 \\
\text { fanuary }\end{array}$} \\
\hline & fuly & October & fanuary & May & September & \\
\hline $\begin{array}{l}\text { Trapezium } \\
\text { Esternocleidomastoid (ECM) }\end{array}$ & $\begin{array}{l}50 \text { UI BOTOX } \\
\text { (each trapezium) }\end{array}$ & $\begin{array}{l}30 \text { UI BOTOX }^{\circledR} \\
\text { (right trapezium) } \\
30 \text { UI BOTOX } \\
\text { (each ECM) }\end{array}$ & $\begin{array}{l}30 \text { UI BOTOX }^{\circledR} \\
\text { (each trapezium) } \\
30 \text { UI BOTOX } \\
\text { (Each ECM) }\end{array}$ & $\begin{array}{l}20 \mathrm{UI}^{\text {BOTOX }}{ }^{\circledR} \\
\text { (each trapezium) }\end{array}$ & $\begin{array}{l}20 \text { UI BOTOX }^{\circledR} \\
\text { (each trapezium) }\end{array}$ & $\begin{array}{l}10 \mathrm{UI}^{\mathrm{BOTOX}}{ }^{\circledR} \\
\text { (each trapezium) }\end{array}$ \\
\hline Paracervical musculature & & & & & $\begin{array}{l}20 \text { UI BOTOX } \\
\text { (each side) }\end{array}$ & $\begin{array}{l}15 \text { UI BOTOX }^{\circledR} \\
\text { (each side) }\end{array}$ \\
\hline
\end{tabular}

The patient received 50 IU BOTOX ${ }^{\circledR}$ (Allergan) in three different locations of each trapezium on 17 July 1996; on 24 October 1996, 30 IU BOTOX were administered in each esternocleidomastoid and $30 \mathrm{IU}$ in right trapezium; on 22 January $199730 \mathrm{IU}$ BOTOX were given in each esternocleidomastoid and trapezium; on 21 May 199720 IU BOTOX were given in each trapezium; on 25 September 199740 IU BOTOX were given in each trapezium and bilateral paracervical musculature (total $80 \mathrm{IU}$ ); on 15 January 199810 IU BOTOX were given in each trapezium and 30 IU in paracervical musculature bilaterally. 